\title{
CBT based comprehensive psychotherapy in an elderly female with resistant chronic depression.
}

\author{
Shreya Manot ${ }^{1}$, Susmita Halder ${ }^{2}$ \\ ${ }^{1}$ Clinical Psychologist, Kolkata. \\ ${ }^{2}$ Associate Professor, Department of Psychology, St. Xavier's University, Kolkata. \\ Corresponding author: Susmita Halder \\ Email: susmitahalder@gmail.com
}

\begin{abstract}
Background: The population of the elderly has been on the rise in recent years and this demographic trend is likely to continue. Depression tends to be common in the elderly. Further it is possible that cognitive abilities start deteriorating as a result of depression and even more so due to several changes that are already occurring. This may impact an individual's cognition, functionality, and autonomy, may progress from a subclinical level to a pathological level if not intervened early. Medications work to reduce symptom severity but sometimes patients become resistant to it and other interventions have to be used. CBT techniques have been found to be effective to treat depression and further efficacy of reminiscence therapy for older adults with mild to moderate depression has been established.

Method: The present study was undertaken with the objective of establishing the efficacy of a comprehensive psychotherapy program for an elderly woman, aged 66 years, who presented with a diagnosis of chronic depression, along with chronic pain and sub clinical cognitive limitations. Techniques of CBT, reminiscence therapy and cognitive training was carried out for 8 weekly sessions.

Results: The outcome of the intervention showed improvements in overall functioning along with generalization of the training, thereby implicating the effectiveness of the intervention.

Conclusion: Thus, it is important to promote active aging, fostering healthy mental functioning and training the cognitive capabilities, to avoid pathological aging or reducing its impact.
\end{abstract}

Key words: Elderly, Cognitive training, CBT, Reminiscence therapy, Depression.

(Paper received $-28^{\text {th }}$ August 2021, Peer review completed $-10^{\text {th }}$ September 2021)

(Accepted $-15^{\text {th }}$ September 2021)

\section{INTRODUCTION}

The population of the elderly has been on the rise in recent years due to the impressive gains that society has made in terms of increased life expectancy [1]. Although many elderly individuals remain physically and psychologically healthy, aging is usually related to decline and losses of various kinds: mood related, physical and cognitive changes being few of them. Depression tends to be common in the geriatric population and often presents in a different way which is often confused with other concomitant medical conditions thereby hindering the intervention [2]. The presentation, etiology, risk and protective factors, and potential outcomes all reflect aspects of the older adult's lifespan trajectory [3]. Ageing encompasses changes in physical, psychological and social realms of an individual. Concerns with the dwindling health and presence of any medical issues make the geriatric population prone to develop mental health conditions [4]. It is possible that cognitive abilities start deteriorating as a result of depression [5] and even more so in the elderly, due to several changes that are already occurring. This may impact an individual's cognition, functionality, and may progress from a subclinical level to a pathological level if not intervened early. 
Depression tends to be amenable to treatment in almost sixty five to seventy five percent of the elderly [6]. Conventionally medications work to reduce symptom severity in the elderly as effectively as it does in the younger population but sometimes patients become resistant to it owing to several reasons and other interventions have to be used. There are different types of non-pharmacological interventions that can be provided to ensure healthy mental and cognitive functioning. Therapy generally results in improved quality of life, enhanced functional capacity, and possible improvement in medical health status, increased longevity, and lower health care costs [7]. Cognitive behavioural therapy has been established as an effective treatment option for older people with depressive disorder and appears to be associated with its specific effect $[8,9]$. Also reminiscence therapy has been designed specifically for older adults with mild to moderate depression. It aims to prevent or reduce depression, increase life satisfaction, improve self-care, improve selfesteem, and help older adults cope with crises, losses, and life transitions. Further cognitive training has often been found to be suitable and it appeared to optimize cognitive functions [10] for the healthy elderly as well. These kinds of programs are hypothesized to impact on cognitive reserve, which is generally known to delay the cognitive and functional expression of neurodegenerative diseases. Although research bases exists for the efficacy of these interventions, there tends to be a paucity of studies on overall packages for the elderly diagnosed with depression and other problems. Thus the present study was carried out with the aim of examining the implication of a comprehensive CBT based psychotherapeutic programme in an elderly with depression, over a span of 10 sessions.

\section{METHODS:}

Details of the case: In the present cases study, a 66 year lady, residing in an urban area of Kolkata, educated up to class IX, unmarried, with a diagnosis of Major depressive disorder, was presented with the complaints of having body aches last since 8-9 years with an increase since last one year, forgetfulness, low mood, feeling lonely, feeling worthless, inability to do her daily activities without help and difficulty in falling asleep at night since last one year six months. She was on psychiatric medications since a long time, however reported of no significant improvement in her condition. On further probing and administration of a set neuropsychological assessments, she showed subclinical difficulty in certain areas of cognitive functioning.

Procedure: After obtaining permission and informed consent to begin the intervention from the client, to begin the intervention an intervention plan was planned in terms of an overall package to target different areas. Further baseline and post treatment assessments by psychological assessments were carried out to ascertain the impact of the intervention. Modifications were made to the plan as and when required depending on situational or client related factors. Ethical consideration and confidentiality was maintained.

Intervention Plan: The entire process involving the intervention package was planned to continue over a duration of 3 months by a trained therapist and would be spread across 10 weekly sessions. The therapist would provide one session per week for a duration of forty-five minutes. In every session homework assignments would be provided to the client for the entire week. The different components of Cognitive Behavioural Therapy (CBT), Reminiscence therapy and Cognitive tasks to be used were planned ahead of time in terms of level of difficulty and complexity of matter.

The therapeutic goals were based on reducing the somatic concerns, distress, low mood, negative thoughts and increase perception of positive experiences along with improving cognitive functioning and enhancing coping skills.

Detailed intervention Package: The initial baseline assessments were done. Following which the intervention started with psychoeducation, providing information about depression and chronic pain to increase the insight and facilitate a better understanding in the client.

Cognitive-behavioural therapy: To improve the patient's feeling of worthlessness and poor motivation, the focus was on facilitating an identification of her dysfunctional beliefs and their role in overall symptomatology, using Socratic questioning. This would enable working with her underlying thoughts at the same time as increasing life satisfaction, take a different view of her life. These included: 
Table 1: Table showing the components used for the somatic complaints of the present client.

\begin{tabular}{|l|l|}
\hline TECHNIQUE & DESCRIPTION \\
\hline BATHE technique & $\begin{array}{l}\text { To improve her coping with complains of severe pain, the BATHE technique was } \\
\text { used along with explaining the pain cycle and how it was working her case: }\end{array}$ \\
$\begin{array}{l}\text { B- Understanding the background of symptom formation of pain, thereby making } \\
\text { the client more aware of its chronicity } \\
\text { A - Then an understanding was established of her affect associated with the pain } \\
\text { and what meaning she makes of it. }\end{array}$ \\
$\begin{array}{l}\text { T- Segregating the pain symptoms in a hierarchy the client was assisted to develop } \\
\text { a new approach in reacting to her symptoms. }\end{array}$ \\
$\begin{array}{l}\text { H- An understanding of how she wasn't following the doctor's guidelines to } \\
\text { reduce pain was beneficial in reducing her complaints. }\end{array}$ \\
$\begin{array}{l}\text { E- Finally expressing empathy and an understanding of the severity of her pain } \\
\text { and distress, the therapist motivated the client to follow her medical regimen more } \\
\text { regularly, as it was a genuine physical problem. }\end{array}$ \\
\hline
\end{tabular}

Reminiscence therapy: The client had a bias towards negative events. To target the depressive symptoms it was therefore essential to change her view of her own life. During reminiscence therapy the client reconstructed her life story and examined both positive and negative experiences, with the therapist. It included:

Flow chart 1: Flow chart showing the components of Reminiscence therapy used for the present client:

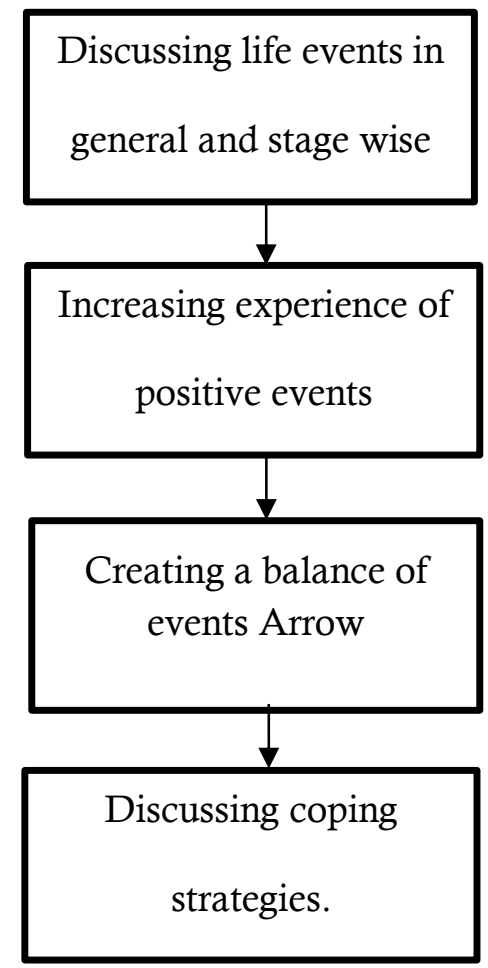

Cognitive training: A cognitive training program consisting of customized tasks targeting specific cognitive functions was also applied to improve her functioning. 
Termination of therapy: All the therapy sessions till present day were summarized. She mentioned how the therapy benefitted her and where all she would get stuck. These were further discussed. Her current status was assessed by conducting the post intervention assessments. She was motivated to use her skills to cope with any future difficulties and was informed about termination of therapy.

Outcome of therapy: Over the 10 sessions of the intervention provided, the clients overall functioning had improved. There was a reduction in client's low mood and experience of distress as can be seen from table 4. Overall the client reported of feeling less lonely, having a better understanding of her pain and being able to do more tasks for herself as compared to before.

Table 4: Table showing changes in pre and post intervention measure.

\begin{tabular}{|c|c|c|c|c|c|}
\hline \multicolumn{6}{|c|}{ QUANTITATIVE } \\
\hline \multicolumn{3}{|c|}{ Measure } & \multicolumn{2}{|c|}{ Pre intervention } & Post intervention \\
\hline \multicolumn{3}{|c|}{ Geriatric Depression Scale } & \multicolumn{2}{|c|}{10} & 9 \\
\hline \multirow{2}{*}{$\begin{array}{l}\text { Brief pain } \\
\text { inventory }\end{array}$} & \multicolumn{2}{|c|}{ Pain } & \multicolumn{2}{|l|}{7} & 6 \\
\hline & \multicolumn{2}{|c|}{ Pain interference } & \multicolumn{2}{|l|}{6} & 4 \\
\hline \multicolumn{3}{|c|}{ Trail making test-A } & \multicolumn{2}{|c|}{81 seconds } & 65 seconds \\
\hline \multicolumn{3}{|c|}{ Trail making test $-\mathrm{B}$} & \multicolumn{2}{|c|}{279 seconds } & 223 seconds \\
\hline \multirow{2}{*}{$\begin{array}{l}\text { Wechsler } \\
\text { Memory } \\
\text { Scale }\end{array}$} & \multicolumn{2}{|c|}{ Logical memory test } & \multicolumn{2}{|c|}{18} & 24 \\
\hline & \multicolumn{2}{|c|}{$\begin{array}{c}\text { Verbal paired } \\
\text { associates test }\end{array}$} & \multicolumn{2}{|l|}{24} & 31 \\
\hline \multicolumn{6}{|c|}{ QUALITATIVE } \\
\hline \multicolumn{2}{|c|}{ Measure } & \multicolumn{2}{|c|}{ Pre intervention } & \multirow{2}{*}{\multicolumn{2}{|c|}{$\begin{array}{l}\text { Post intervention } \\
\text { More relaxed and open, } \\
\text { talking by herself }\end{array}$}} \\
\hline \multicolumn{2}{|c|}{ Participation } & \multicolumn{2}{|c|}{$\begin{array}{c}\text { Hesitant and only } \\
\text { answering to questions }\end{array}$} & & \\
\hline \multicolumn{2}{|c|}{$\begin{array}{l}\text { Initiation of } \\
\text { conversation }\end{array}$} & \multicolumn{2}{|c|}{ Absent } & \multicolumn{2}{|c|}{ Present } \\
\hline \multicolumn{2}{|c|}{ Facial expression } & \multicolumn{2}{|c|}{$\begin{array}{c}\text { Mostly fixed and } \\
\text { indicative of low mood }\end{array}$} & \multicolumn{2}{|c|}{$\begin{array}{l}\text { More variable and suited } \\
\text { to situation }\end{array}$} \\
\hline \multicolumn{2}{|c|}{ Crying spells } & \multicolumn{2}{|c|}{ Frequent } & \multicolumn{2}{|c|}{ Significantly reduced } \\
\hline \multicolumn{2}{|c|}{ Social behaviour } & \multicolumn{2}{|c|}{$\begin{array}{c}\text { Avoidant, Had a } \\
\text { negative approach }\end{array}$} & \multicolumn{2}{|c|}{$\begin{array}{l}\text { Started initiating contact } \\
\text { with others on her own }\end{array}$} \\
\hline
\end{tabular}

\section{DISCUSSION}

The application of a comprehensive psychotherapy package on the present client yielded significant results in terms of her overall functioning and reduction in symptoms. A focus linking the behaviour, thought and mood states, and further taking a life review in the present case study, the client's experience of low mood was targeted, and it resulted in a reduction of the same, as clinically observed and reported by the client. Many studies showed that reminiscence therapy resulted in statistical significantly decrease in depression [11]. Thereby showing the efficacy of a combination CBT and reminiscence therapy for an elderly patient diagnosed with depression. One striking finding in the present study was that even though her scores on measures of depression and pain did not improve much post intervention, there were observable differences as seen in table 4 . This highlights that the impact of psychotherapy in elderly may be beneficial in many other ways apart from their subjective reporting's of low mood, at times. Psychotherapy is viewed as effective treatment for depression, but its efficacy in older people is not well defined [12]. This was also quantified by using the clinical rating scales and the Visual Analogue Scale, where in the experienced distress reduced over the sessions. To be suitable for the client the package was customized, and modifications were made to the structured format protocols. Further the related cognitive difficulties were also addressed using the structured cognitive training program, which included many real-life related tasks, as a result of which the present client showed generalization of the training in her daily life. These kinds of programs are hypothesized to impact on cognitive reserve, which is an important concept in aging and functions by optimizing normal performances in the elderly [13-15]. 
Thus, although the efficacy of all of the psycho-therapy component used in the present case have been already established individually, the present study goes forward and highlights the effectiveness of a comprehensive package for the elderly. Owing to several individual factors as well as different presentation and treatment adherence in this population, a comprehensive tailoring of the treatment is required to obtain optimum results. Keeping this in mind, more such intervention plans can be tailor made, within the standardized framework to address the various mental health problems in the elderly. To ensure greater generalizability of the findings there is thus a need to study and apply a similar intervention plan in the future, across a greater number of individuals.

\section{REFERENCES}

1. Kinsella KG, Velkoff VA. An aging world: 2001. Bureau of Census; 2001.

2. Halder S, Manot S. Identifying suicidal risk and its association with depression in the elderly population. J Geriatr Ment Health 2020;7(1):29-33.

3. Fiske A, Wetherell JL, Gatz M. Depression in older adults. Ann Rev Clin Psychol 2009;5:363-89.

4. Halder S, Mahato AK. Cognition in Ageing: Implications for Assessment and Intervention. In Handbook of Research on Geriatric Health, Treatment, and Care 2018 (pp. 118-133). IGI Global.

5. Rodda J, Walker Z, Carter J. Depression in older adults. BMJ 2011;343.

6. Alexopoulos GS, Katz IR, Reynolds 3rd CF, Carpenter D, Docherty JP, Expert Consensus Panel for Pharmacotherapy of Depressive Disorders in Older Patients. The Expert Consensus Guideline Series. Pharmacotherapy of depressive disorders in older patients. Postgrad Med 2001;10;1-86.

7. Birrer RB, Vemuri SP. Depression in later life: a diagnostic and therapeutic challenge. Amer Fam Physician 2004;69(10):2375-82.

8. Serfaty MA, Haworth D, Blanchard M, Buszewicz M, Murad S, King M. Clinical effectiveness of individual cognitive behavioral therapy for depressed older people in primary care: a randomized controlled trial. Arch Gen Psychiatry 2009;66(12):1332-40.

9. Levendusky PG, Hufford MR. The application of cognitive-behavior therapy to the treatment of depression and related disorders in the elderly. J Geriatr Psychiatry 1997;30(2):227-38.

10. Belleville S, Gilbert B, Fontaine F, Gagnon L, Ménard É, Gauthier S. Improvement of episodic memory in persons with mild cognitive impairment and healthy older adults: evidence from a cognitive intervention program. Dement Geriatr Cogn Disord 2006;22(5-6):486-99.

11. Hsieh HF, Wang JJ. Effect of reminiscence therapy on depression in older adults: a systematic review. Int J Nurs Stud 2003;40(4):335-45.

12. Peng XD, Huang CQ, Chen LJ, Lu ZC. Cognitive behavioural therapy and reminiscence techniques for the treatment of depression in the elderly: a systematic review. J Int Med Res 2009;37(4):975-82.

13. Tardif S, Simard M. Cognitive stimulation programs in healthy elderly: a review. Int J Alzheim Dis $2011 ; 1$.

14. Le Carret N, Lafont S, Letenneur L, Dartigues JF, Mayo W, Fabrigoule C. The effect of education on cognitive performances and its implication for the constitution of the cognitive reserve. Dev Neuropsychol 2003;23(3):317-37.

15. Stern Y. The concept of cognitive reserve: a catalyst for research. J Clin Exp Neurospsychology 2003;25(5):58993.

$* * * * * * * * * * * * * * * * * * * * * * * * * * * * * * * * * * *$

Acknowledgements - Nil

Conflict of Interest - Nil

Funding - Nil. 